\title{
Pediatric Coronary Artery Revascularization Surgery: Development and Effects on Survival, Cardiac Events and Graft Patency for Children With Kawasaki Disease Coronary Involvements
}

\author{
Soichiro Kitamura ${ }^{1, *}$ \\ ${ }^{1}$ National Cerebral and Cardiovascular Center, Osaka, Japan \\ *Corresponding author: Soichiro Kitamura, National Cerebral and Cardiovascular Center, Osaka, Japan. E-mail: skitamur@hsp.ncvc.go.jp \\ Received 2015 August 18; Accepted 2015 September 8.
}

\begin{abstract}
Pediatric coronary artery bypass surgery gained wide acceptance with the introduction of internal thoracic arteries (ITAs) for bypass operations for post Kawasaki disease (KD) lesions. The technique is now established as the standard surgical choice, and its safety even in infancy, graft patency, growth potential, graft longevity and clinical efficacy have been well documented. In this article the author reviews the development of pediatric coronary bypass as the main indication for the treatment of coronary lesions due to KD. I believe that coronary revascularization surgery in pediatric population utilizing uni- or bilateral ITAs is the current gold-standard as the most reliable treatment, although percutaneous coronary intervention with or without a stent has been tried with vague long-term results in children.
\end{abstract}

Keywords: Coronary Bypass, Pediatrics, Kawasaki Disease, ITA (Internal Thoracic Artery), Saphenous Vein Graft, Graft Patency, Long-Term Survival, Cardiac Events

\section{Introduction}

In 1967 Kawasaki (1) reported a previously unrecognized acute febrile illness with muco-cutaneous lesions and lymphadenopathy (MCLS or MLNS), popularized later as Kawasaki disease (KD). Death in affected children was soon recognized as primarily due to inflammatory coronary aneurysm formation $(2,3)$. Rupture of coronary aneurysms in the acute phase and thrombosis or fibroproliferative narrowing of the coronary artery in the convalescent and late phases of the disease were the main cardiac sequelae and cause of death. Acute myocardial infarction due to $\mathrm{KD}$ and the resulting high death rate in children $(4,5)$ became recognized as a social crisis for Japan in the 1970s and 1980s, however, there had been no reports of attempted pediatric coronary revascularization surgery, and the prevailing opinion in Japan was that surgery had little to offer for this acute inflammatory condition.

In 1986, Kato et al. (6) published the first evidence that significant coronary artery lesions persisted in children after the convalescence stage of the acute illness. In such children, acute myocardial infarction caused mortality as high as $65 \%$ after the 2 nd or 3rd myocardial infarction episode (6). In the reports published in the late seventies, coronary artery imaging depended on aortic root injec- tion of contrast, which provided limited detail. Selective coronary arteriography (sCAG) was not performed in children, because there were no compelling indications coupled to concerns about possible higher complication rates for small children. However, to determine potential targets for surgical treatment in children, sCAG was considered essential.

\section{Findings by Selective Coronary Arteriography in KD Children}

We started sCAG in small children by using a 4 or 5F handmade catheter shaped like the Judkins coronary catheters with size and curve adjustments fashioned by superimposing catheters on the lateral chest $\mathrm{x}$-ray films of the subject child (7). Although a variety of coronary lesions were identified among individuals with $\mathrm{KD}$, obstructive lesions most commonly involved the entry or the exit portions of coronary aneurysms which were most often located on the proximal coronary arteries, i.e. the left main trunk, particularly in the left coronary system $(8,9)$. On the other hand, right coronary artery lesions tended to involve more distal areas before and sometimes beyond the bifurcation. These findings undermined the initial belief that surgical

Copyright (C) 2016, Growth \& Development Research Center. This is an open-access article distributed under the terms of the Creative Commons Attribution-NonCommercial 4.0 International License (http://creativecommons.org/licenses/by-nc/4.0/) which permits copy and redistribute the material just in noncommercial usages, provided the original work is properly cited. 
indications would be quite rare in KD. Surgical coronary revascularization was soon accepted as having a role in $\mathrm{KD}$ management and was included in the treatment guidelines for KD in Japan (10).

\section{Graft Selection in Pediatric Coronary Revascularization}

The first case of surgical coronary revascularization for KD was performed in 1975 on a 4-year-old boy who had had an anteroseptal myocardial infarct after acute KD. The sCAG showed total occlusion of both the left anterior descending (LAD) and right coronary arteries (RCA) with a reduced left ventricular ejection fraction (LVEF) of 0.45. At operation, an autologous saphenous vein graft (SVG) was harvested from the thigh, and two aortocoronary bypass grafts performed. Postoperative angiograms revealed excellent graft patency with an improved LVEF of 0.61 . This patient was reported as a first successful case (11).

Unfortunately however, both grafts totally occluded within a year and the child only survived because collateral vessels developed from the circumflex artery to the LAD and bridging collaterals from the proximal RCA to the distal RCA. The LVEF again deteriorated. The first pediatric coronary artery bypass grafting (CABG) utilizing the autologous SVG ultimately proved unsuccessful at 1 year following surgery. Another young man (26-year-old) who had had an anterior myocardial infarct due to a left main-LAD aneurysm with a severe stenosis at the LAD origin underwent aortocoronary SVGs (12). Ten years later, both grafts were found closed and his LV (left ventricle (cular)) function had deteriorated to the level that heart transplantation was indicated. Because the KD patient is usually a child, expected graft patency must be prolonged and the SVG proved unsatisfactory. During the late seventies and early eighties in Japan, SVGs were exclusively used as a bypass graft for adult atherosclerotic coronary artery disease. At this time the land-mark paper recommending internal thoracic artery (ITA) grafts in adult CABG by Loop and coworkers (13) had not been published. Another unresolved was how grafts would respond to the somatic growth of children. We decided to use a pedicled ITA which was rarely involved in KD arteritis and was also expected to grow when used in growing children. We reported the first successful cases with the use of ITA grafts in children in 1985 (14). In addition, we demonstrated the safety of bilateral use of the ITA without any visible compromise of thorax growth (15). Subsequently, we have promoted ITA grafts as the best option in pediatric CABG. In 1990, Takeuchi et al. (16) successfully used the gastroepiploic artery (GEA) for a child with a KD coronary lesion.

The ITA of small children is a short, thin-walled artery with a diameter of $1 \mathrm{~mm}$ or less reflecting a child's small thorax compared to the large head. It requires meticulous and precise dissection under high magnification surgical glasses or microscope (17) with 9 - 0 or 10 - 0 small needles and sutures. Use of a surgical microscope is uncommon for adult CABG, but for pediatric CABG, it may be an important tool. Vida et al. (18) recently also utilized a microscope for an infant case with success.

\section{Growth Response of Grafts in Children}

As reported previously $(19,20)$, graft length was measured utilizing the 3-dimensional Pythagorian rule applied to the bilateral angiograms. These measurements showed that in children the ITA graft could grow in accord with somatic growth, in contrast the SVG although autologous in origin had poor growth potential in length in proportion to body size in children $(19,20)$. For this reason coronary artery distortion due to tenting or traction was observed in the late postoperative period with resulting obstruction or restricted flow in the coronary artery distal to the anastomotic site even though the SVG was patent (20-22).

\section{The Negative Aspects of the ITA Graft}

Flow competition causing a string phenomenon of the ITA graft is now well documented and occurs because of insufficient blood flow through the graft when the recipient coronary artery blood flow is unrestricted (23). This phenomenon has also been observed in adult CABG for atherosclerotic disease and is the major non-technical cause of ITA graft failure (thrombosis). However, in pediatric CABG, recanalization of ITA grafts which had been judged as occluded or nonfunctioning following the ITA string phenomenon occurred with a relatively high incidence of 20 - 25\% (23-25) compared to that for adult CABG. This phenomenon is endothelium dependent and when flow competition between the graft and the recipient coronary artery disappears by progression of coronary artery obstructive lesions, the ITA regains its flow and function as a graft unless the lumen is completely thrombosed (26).

Measurements of the fractional flow ratio (FFR) with a pressure guide wire may help avoid the ITA string phenomenon due to flow competition. Ogawa et al. (27) reported that an abnormal preoperative FFR normalized following successful CABG in KD patients. Botman et al. (28) studied the value of FFR $(>0.75$ or $\leq 0.75)$ for ITA graft obstruction in adult CABG and reported that $8.9 \%$ of the bypass grafts in functionally significant lesions (> 0.75 ), and $21.4 \%$ of the bypass grafts in functionally nonsignificant lesions $(\leq 0.75)$ were occluded. There was no difference in angina class between the groups. Recently, Ferguson et al. (29) reported on the value of FFR measurement in anticipating graft closure or nonfunctioning state in adult CABG. The usefulness of FFR in preventing the graft string phenomenon in pediatric coronary artery disease with multiple aneurysms needs further prospective evaluation, and it would be worthwhile to do as a multicenter trial. Anastomotic stenosis due to 
technical reasons can be easily managed by a simple balloon dilatation with essentially no recurrence of stenosis $(30,31)$. Stenting is unnecessary in this setting and should be avoided in children.

\section{Long-Term Patency and Graft Morphology in Growing Children}

When SVG and ITA long-term graft patency in pediatric CABG were compared ITA patency was far better than the SVG for both the LAD and non-LAD coronary arteries (24, 30-32) (Figure 1). Recently, patency of ITA grafts for KD have shown no significant differences between the LAD and non-LAD target coronary arteries (32) and between younger ( $<10$ years old) and older children (10 years old) (24) (Figure 2 ). ITA grafts patent at 1 year after surgery remained so for up to 25 years (24) and I believe they will continue to do so for the entire life of the patients. The ITA string sign followed by occlusion occurred within a year after surgery (23) and the SVG closed within a year as well as late after the operation due to intimal fibro proliferation eventually resulting in atherosclerosis $(22,24,33)$.

Late postoperative angiographic graft morphology was quite different between the SVG and ITA. The wall configuration of the ITA graft was smooth with no luminal stenosis or dilatation and well matched in size with that of the recipient coronary artery area 20 years after the operation $(21,24)$. In addition, the graft length grew in proportion to the patient body growth $(24,30$, 31). In contrast, the SVG was usually dilated with a local narrowing and was sometimes aneurysmal with prominent irregularity of the wall contour $(22,24)$. Patients in their twenties showed fibro proliferative thickening and atherosclerotic changes with mural thrombosis (22, $24,33)$. The SVG could also be a cause of acute myocardial infarction in the late postoperative period probably due to embolism from wall thrombus detachment or thrombosis at the site of intimal thickening. Because of the poor growth potential of SVGs, they could cause traction on the recipient coronary artery distorting the anastomosis, resulting in poor run-off to the distal artery $(20,21)$. The representative graft-coronary angiograms in the late postoperative period ( $>20$ years) are shown in Figure 3.

With enlarged ITA grafts in association with a patent SVG, five grown-up patients who had had total occlusion of both the left and right coronary ostia are living at present without symptoms. In summary it is evident that the 25-year patency rate for the ITA graft was $87 \%$ compared with $42 \%$ for the SVG, and when used in children of less than 10 years of age, patency for ITA grafts was $86 \%$, essentially the same as that of the whole age group, compared to $25 \%$ for the SVG ( $\mathrm{P}<0.001)(24)$. From the 30-year post-operative follow up it is concluded that the pedicled ITA would be the conduit of choice for pediatric $C A B G$, based on ensuring persistent graft patency, growth potential and possible metabolic benefits for many decades (26).

Figure 1. Long-Term Patency of ITA, GEA and SVG for Non-LAD Vessels

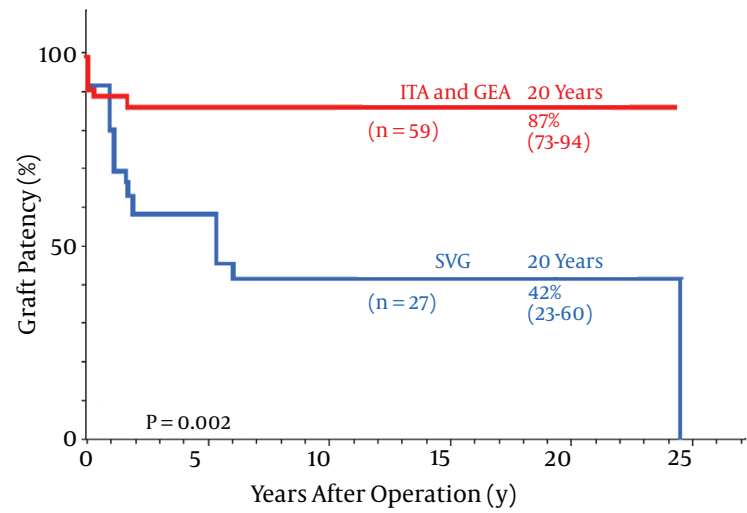

For the LAD, ITA was exclusively used and use of SVG was infrequent. The ITA remained constantly patent after 1 year and there was no difference in ITA patency between all the target vessels including the LAD and nonLAD target vessels; 87\% (95\% CI 78 - 93) vs. 87\% (95\% 73 - 94). In contrast SVG patency declined progressively over 20 years. The difference in patency between two different grafts was highly significant at $\mathrm{P}=0.002$; $\mathrm{CI}$, confidence interval; GEA, gastroepiploic artery; LAD, left anterior descending; copyright permission obtained from the American Heart Association for reference (24)

Figure 2. The Difference in Graft Patency According to the Age of Patients at Operation (10 or $<10$ years)

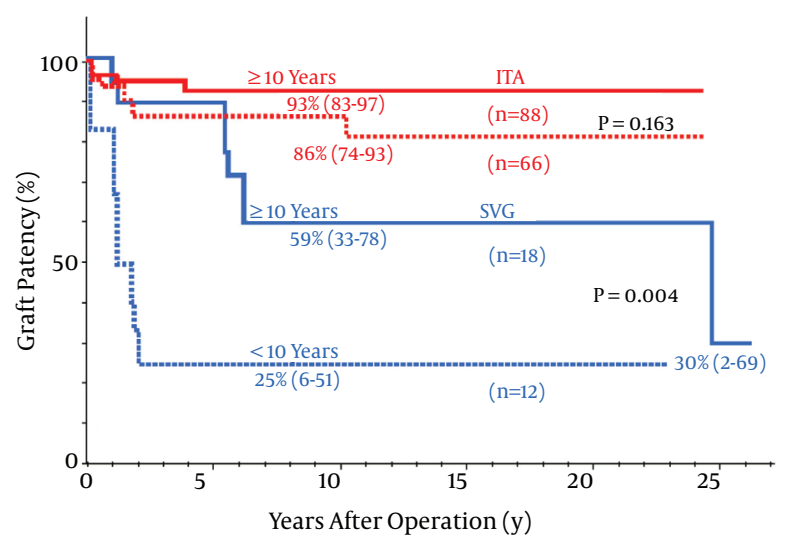

Long-term patency for the ITA was not significantly different between the patients aged 10 years (93\%) and $<10$ years ( $86 \%$ ) at $\mathrm{P}=0.163$, whereas SVG patency was significantly lower for the younger patients aged $<10$ years (25\%) than for the older children 10 years (58\%) at $\mathrm{P}=0.004$; copyright permission obtained from the American Heart Association for reference (24). 
Figure 3. Representative Graft-Coronary Angiograms in the Late Postoperative Period ( $>20$ Years)
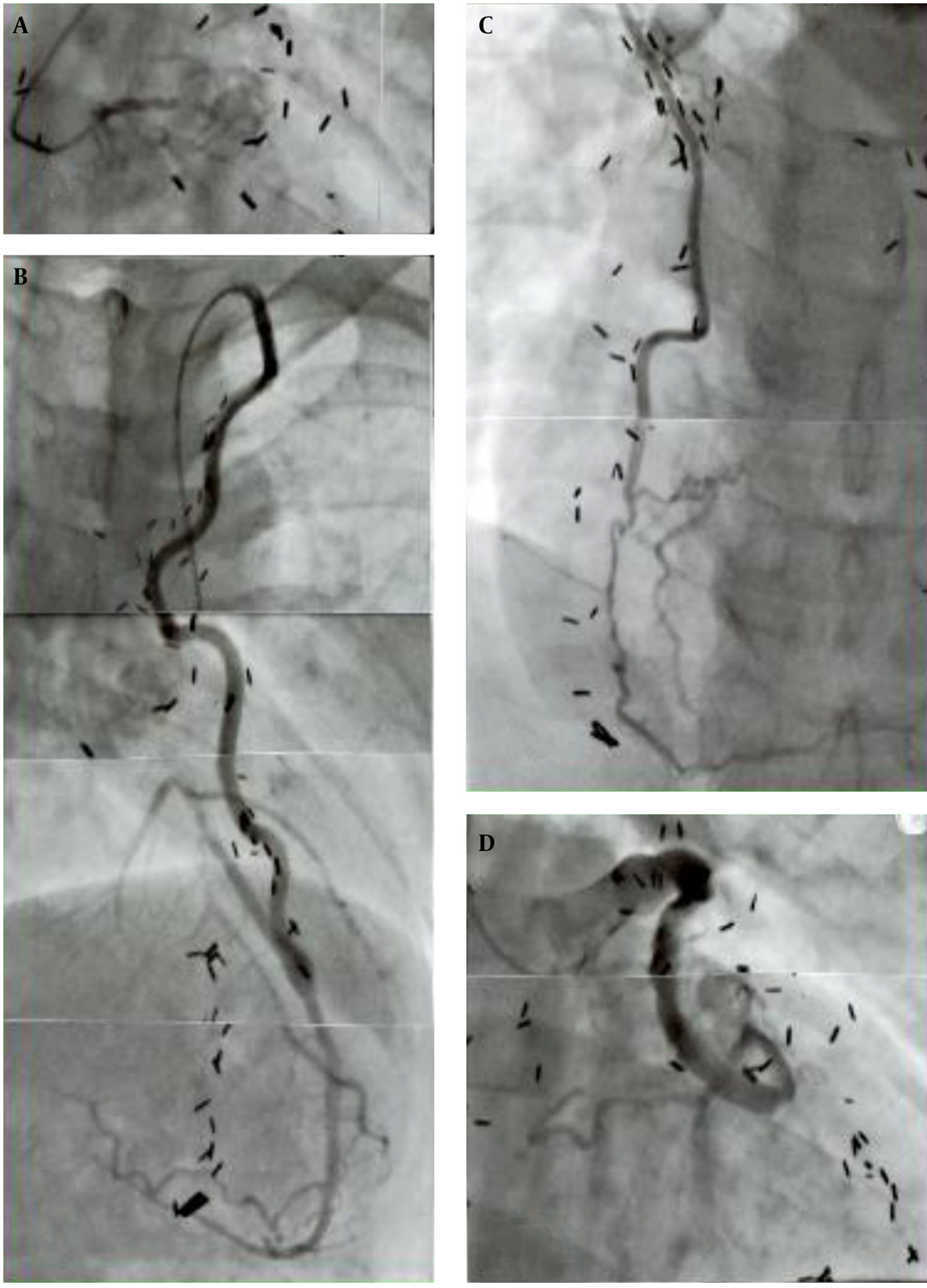

The boy received a triple bypass grafting at age 12 years for coronary lesions due to KD, his bilateral coronary ostia or very proximal main trunks had been totally obstructed (A); he sustained an acute myocardial infarct due to SVG-LCX artery thrombosis that occurred 24 years after the operation (D); fortunately, bilateral ITAs (LITA-LAD, RITA-RCA) were well patent (B, C) and the patient survived without complication; thrombolysis of the SVG was successfully carried out. Note the difference in configuration and wall characteristics of the ITA (B, C) and SVG (D) 24 years after the operation; presence of old SVG itself can be a cause of acute myocardial infarction; A, total obstruction of the left main trunk; B, left internal thoracic artery (LITA)-left anterior descending artery (LAD); C, right internal thoracic artery (RITA)-right coronary artery (RCA); D, saphenous vein graft (SVG) -left circumflex artery (LCX). 


\section{Survival of KD Children Treated by Pediatric CABG}

Pediatric coronary bypass surgery using arterial grafts is a safe procedure for children with severe coronary involvements due to $\mathrm{KD}$. The surgical mortality with more than 100 such children has been $0 \%$, and the late mortality during the next 25 years was 5\% (95\% CI: 2 - 12) (24) (Figure 4). Successful surgery may also improve cardiac function (34). Approximately one-third of the surgical subjects had had previous myocardial infarction (24). Although a strict comparison is impossible, 30-year survival of KD children with previous myocardial infarction was limited, being as low as 49\% (95\% CI: 27 71) (35, 36), compared with a 95\% (95\% CI: 88 98) 25 - 30 year survival with surgical coronary revascularization (24). Late death after CABG for KD children was frequently sudden mostly occurring in children having both reduced LV function and a history of ventricular tachycardia $(24,35)$.

Therefore, early management may be important; such as early reintervention for graft failure (37) and electrophysiologic studies, and early ablation therapy or ICD implantation for ventricular tachycardia.

Figure 4. The Long-Term Survival Rate of 114 Patients

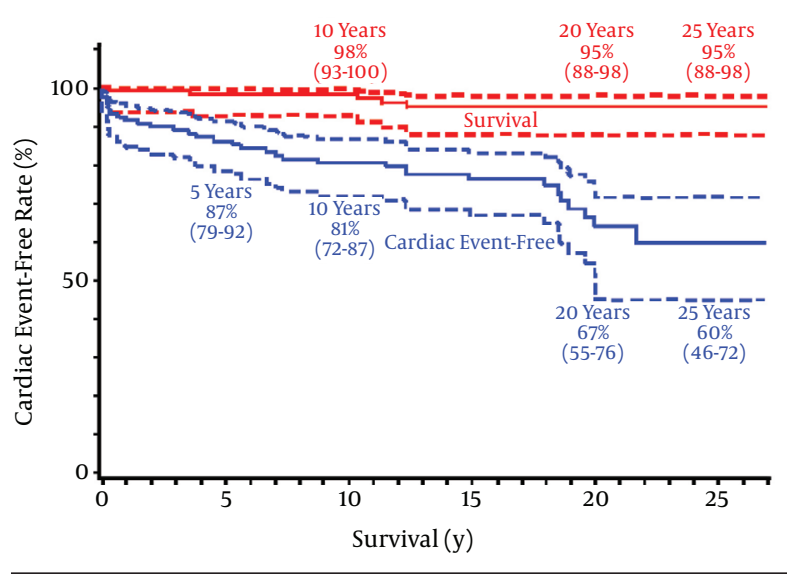

There were 5 deaths during follow-up, all deaths seemed to be cardiac in origin, survival at both 20 and 25 years was 95\% (95\% CI, 88 to 98); the cardiac event-free rate is also shown; cardiac events occurred 35 times in 32 patients during the follow-up term; the 20- and 25-year cardiac event-free rates were $67 \%$ (95\% CI, 55 to 76 ) and $60 \%$ (95\% CI, 46 to 72 ), respectively. Importantly, there was a trend for the cardiac event-free curve to decline slowly but progressively; postoperative $\mathrm{PCI}$ and reoperation were the most common cardiac events during follow-up.

\section{Event Incidence Following Pediatric Bypass Operation for KD}

Cardiac events were precipitated by 1) ITA graft stenosis at the anastomosis, 2) graft obstruction of any cause including the string phenomenon of ITA grafts, 3) fibro proliferative intimal thickening and atherosclerosis of the SVG, 4) late thrombosis of the remaining coronary aneurysms and 5) post inflammatory progression of coronary artery fibro-obstructive disease. The incidence of these coronary events increased as the postoperative period lengthened, and the total cardiac event free rates at 5, 10, 20 and 25 postoperative years were 87, 81, 70 and $62 \%$ (95\% CI: 48 - 74) (24), respectively (Figure 4). Tsuda et al. (36) reported that the 30-year overall cardiac eventfree rate in patients with giant aneurysms was 36\% (95\%CI $28-45, \mathrm{n}=245)$, whereas it was 62\% (95\% CI: 48 - 74, $\mathrm{n}=114$ ) with bypass surgery (24). Although cardiac event-free rates reported in 2 different series were not comparable, surgical patients who almost always had had multiple giant aneurysms did have fewer cardiac events during the next 25 to 30 years.

Although cardiac events at 25-year were not uncommon, events resulting in death were rare in surgical patients when early and adequate interventions either by reoperation or percutaneous coronary intervention (PCI) were undertaken $(24,37)$. Furthermore most of the patients had reached adulthood when the second intervention was required. Re-operation utilizing either the radial artery, GEA or both, and PCI using coronary stents could be applied more safely and effectively than in children $(37,38)$.

Analysis of the long-term follow-up data emphasized the need for prolonged close medical supervision of postoperative KD patients either with SVGs or those with persisting patent coronary aneurysms $(24,36,39,40)$. On the other hand, when the graft was functioning well, $84 \%$ of children could enjoy athletic programs at school, and 16\% of them participated in sport clubs (24), although preoperatively all of those patients had been strictly excluded from school athletic programs because of fear of sudden collapse or death in the playground due to repeat coronary events. Once reaching adulthood many patients were successful in holding down jobs and several female patients had successful pregnancies and deliveries. I believe the long-term careful observation shows that pediatric coronary bypass operation with ITA grafts can offer effective and long-lasting treatment and improved quality of life for children compromised by coronary lesions.

\section{Treatment for Coronary Aneurysms With no Stenotic Lesions}

There are no indications for CABG in the absence of stenosis or obstruction. String phenomenon will occur when the ITA is anastomosed to such arteries. In this setting, the main purpose of treatment is to prevent acute thrombotic obstruction within coronary aneurysms. Several interventions have been tried for this purpose in addition to anticoagulation therapy which is mostly based on the combined use of warfarin and aspirin.

\subsection{Ligation of the Outlet of Coronary Aneurysms and Placement of Distal Coronary Bypass Grafts}

Atherosclerotic coronary aneurysms carry a risk of rupture and either resection of the aneurysm or ligation of 
the inlet and/or outlet segments has been performed (41, 42). In contrast, aneurysm rupture has never been experienced in KD except in the very acute inflammatory phase, consequently very few ligations combined with a bypass graft have been done (43) because of the risk of myocardial damage when graft function is not perfect. One patient underwent ligation of the outlet of a right coronary aneurysm with a distal ITA bypass graft, the aneurysm rapidly thrombosed with persistent right bundle branch block, and increased cardiac enzymes. Particularly, when a single ITA is used for a bypass, the initial blood flow may be insufficient for the recipient coronary area because of the initial small caliber of the ITA in children. Also, small side-branches arising from the aneurysm may be simultaneously thrombosed. In my series, I have not ligated the coronary artery, because the ITA string is clinically benign causing no discernible harm except for the mortification of the surgeon. In contrast coronary ligation can lead to some acute cardiac events that may worsen the late prognosis. The surgical strategy for this situation may best involve the use of bilateral ITAs for the same coronary system or use of the bigger SVG despite the likelihood of late SVG failure.

\subsection{Coronary Aneurysmorrhaphy orSize Reduction of Coronary Aneurysms}

This procedure was first reported by Abe et al. (44) who excised the uncalcified anterior wall of a long and large right coronary aneurysm and resutured the wall, maintaining the lumen by a probe of adequate size. The luminal dilatation and irregularity was consequently corrected, resulting in less turbulent blood flow within the aneurysm. This procedure may prevent blood clotting inside the aneurysm, and may be effective in selected patients. Some patients were successfully weaned from warfarin; however, others were complicated by coronary artery thrombosis following the procedure (44), because endothelial function within the aneurysm might have remained impaired. Certainly, a longer follow up with more patients is needed.

\subsection{Use of Covered Coronary Stents}

Covered coronary stents may be suitable for selected patients, particularly for adult KD patients (45). Application of covered coronary stents may not be easy for KD lesions because of the tortuosity, size and length of the coronary lesions, but when feasible, it may prevent coronary thromboembolic obstruction by restoring less turbulent blood flow. Currently, there are few reports concerning this procedure and the late results are quite unknown. I believe that this procedure should also be avoided in growing children.

\section{PCI (Percutaneous Coronary Intervention) for Coronary Obstructive Lesions Due to KD}

The technology of PCI has developed significantly along with that of CABG and it has been effective for KD coronary lesions $(46,47)$. It is obvious that rotablator and/or stenting are more required to the hard fibroproliferative intima and sometimes calcific lesions seen in KD than for atherosclerotic lesions. However, these approaches, particularly stenting, would not be suitable for growing children. Muta and Ishii (47) reported that PCI for KD was less efficacious than CABG because of an increased need for repeat procedures after PCI, particularly when applied in children younger than 12 years old. Coronary revascularization surgery utilizing the ITA should be the gold standard for pediatric patients with KD.

\section{Significance of the Development of Pediatric Coronary Bypass Operation}

In Japan, more than several hundred KD patients have had a bypass operation. The annual number of new KD patients in Japan, mostly children has been increasing progressively for the last two decades. In 2012 in Japan 14,000 new patients were reported and cardiac or coronary lesions were found in $9.3 \%$ in the acute inflammatory phase and this resolved to $2.8 \%$ in the late phase (coronary sequelae) in 2011 (48). The gender ratio remains the same with a ratio of $2: 1$ boy dominance. Recently in the USA, more than 4000 new patients were hospitalized per year $(49,50)$, and reports of pediatric CABG for KD have been increasing significantly from the US, Europe, and Asian countries other than Japan $(51,52)$ Over the last 15 years I have often been consulted by many pediatric cardiologists and surgeons from all over the world including the USA, Canada, South America, Germany, Italy, France, New Zealand, Australia, Turkey, Malaysia, Indonesia, India, Iran, China, Taiwan, Korea, Philippines, Singapore, etc. about surgical indications for their pediatric patients with complications of KD. Severe coronary lesions were often seen and many of them required operation, however, the exact number of such patients in the world is unknown.

Pediatric CABG utilizing the ITA is certainly applicable for coronary artery problems other than KD such as coronary obstruction following arterial switch operation for complete transposition of the great arteries or the Ross procedure, congenital agenesis of the left coronary artery, anomalous origins of the coronary artery, iatrogenic injury of the coronary artery, and other congenital coronary anomalies $(18,51,53-59)$. Mavroudis et al. (51, 54) reported the largest series in the US and expanded the indications for pediatric CABG to congenital coronary anomalies of infants with excellent results. Recently, Viola et al. (55) reported that CABG with ITA grafts was applied to a variety of pediatric coronary lesions with no operative deaths. In addition, at present, there has been essentially no age limitation for this surgery and pediatric CABG with ITA grafts is now successfully carried out in infants $(18,54)$.

The development of pediatric CABG utilizing pedicled 
ITAs for KD coronary lesions and the excellent late surgical results have contributed to standardization of surgical coronary revascularization procedures for children, and the procedure is now frequently the treatment of choice for many disease conditions in children. Sir Magdi Yacoub (60) stated that the work is appraised as "from a mystery to a paradigm" for KD coronary lesions. Vida et al. (18) commented in their recent publication that coronary artery bypass graft operations should represent a fundamental part of the training of contemporary congenital heart surgeons. Pediatric CABG utilizing the ITA, single or bilateral can be applied safely not only to KD patients but even to infants with a variety of pediatric coronary lesions. Its favorable long-term outcome for graft patency, growth potential and long-term clinical efficacy has now been well established.

\section{References}

1. Kawasaki T, Kosaki F, Okawa S, Shigematsu I, Yanagawa H. A new infantile acute febrile mucocutaneous lymph node syndrome (MLNS) prevailing in Japan. Pediatrics. 1974;54(3):271-6. [PubMed: 4153258]

2. Fujiwara H, Hamashima Y. Pathology of the heart in Kawasaki disease. Pediatrics. 1978;61(1):100-7. [PubMed: 263836]

3. Naoe S, Shibuya K, Takahashi K, Wakayama M, Masuda H, Tanaka M. Pathological observations concerning the cardiovascular lesions in Kawasaki disease. Cardiol Young. 2008;1(03):212-20. doi: 10.1017/s1047951100000408.

4. Kato H, Koike S, Yamamoto M, Ito Y, Yano E. Coronary aneurysms in infants and young children with acute febrile mucocutaneous lymph node syndrome. J Pediatr. 1975;86(6):892-8. [PubMed: 236368]

5. Kitamura S, Kawashima Y, Kawachi K, Fujino M, Kozuka T. Left ventricular function in patients with coronary arteritis due to acute febrile mucocutaneous lymph node syndrome or related diseases. Am J Cardiol. 1977;40(2):156-64. [PubMed: 879020]

6. Kato H, Ichinose E, Kawasaki T. Myocardial infarction in Kawasaki disease: clinical analyses in 195 cases. J Pediatr. 1986;108(6):923-7. [PubMed:3712157]

7. Kitamura S, Kawachi K, Shimazaki Y, Fujino M, Yokota K, Ogawa M. [Selective coronary arteriography in pediatric patients (author's transl)]. Kokyu To Junkan. 1980;28(9):1037-40. [PubMed: 7209153]

8. Kitamura S, Kawachi K, Harima R, Sakakibara T, Hirose H, Kawashima Y. Surgery for coronary heart disease due to mucocutaneous lymph node syndrome (Kawasaki disease). Report of 6 patients. Am J Cardiol. 1983;51(3):444-8. [PubMed: 6600576]

9. Kitamura S. Surgical management for cardiovascular lesions in Kawasaki disease. Cardiol Young. 1991;(1):240-53. doi: 10.1017| s1047951100000445.

10. Guidelines for treatment and management of cardiovascular sequelae in Kawasaki disease. Subcommittee of Cardiovascular Sequelae, Subcommittee of Surgical Treatment, Kawasaki Disease Research Committee. Heart Vessels. 1987;3(1):50-4. [PubMed: 3624163]

11. Kitamura S, Kawashima Y, Fujita T, Mori T, Oyama C. Aortocoronary bypass grafting in a child with coronary artery obstruction due to mucocutaneous lymphnode syndrome: report of a case. Circulation. 1976;53(6):1035-40. [PubMed:1083781]

12. Kitamura S, Kawashima Y, Miyamoto K, Kobayashi T, Matsuda H. Multiple coronary artery aneurysms resulting in myocardial infarction in a young man: treatment by double aorta-coronary saphenous vein bypass grafting. J Thorac Cardiovasc Surg. 1975;70(2):290-7. [PubMed:1080226]

13. Loop FD, Lytle BW, Cosgrove DM, Stewart RW, Goormastic M, Williams GW, et al. Influence of the internal-mammary-artery graft on 10-year survival and other cardiac events. $N$ Engl J Med. 1986;314(1):1-6. doi: 10.1056/NEJM198601023140101. [PubMed: 3484393]

14. Kitamura S, Kawachi K, Oyama C, Miyagi Y, Morita R, Koh Y, et al. Severe Kawasaki heart disease treated with an internal mammary artery graft in pediatric patients. A first successful report. $J$ Thorac Cardiovasc Surg. 1985;89(6):860-6. [PubMed:3873581]

15. Kitamura S, Kawachi K, Seki T, Morita R, Nishii T, Mizuguchi K, et al. Bilateral internal mammary artery grafts for coronary artery bypass operations in children. J Thorac Cardiovasc Surg. 1990;99(4):708-15. [PubMed: 2319795]

16. Takeuchi Y, Gomi A, Okamura Y, Mori H, Nagashima M. Coronary revascularization in a child with Kawasaki disease: use of right gastroepiploic artery. Ann Thorac Surg. 1990;50(2):294-6. [PubMed: 2383118]

17. Kitamura S, Taniguchi S, Kawata T, et al. Coronary artery revascularization. Ann Vasc Dis (Myakkan-Gaku).1998;(38):85-90.

18. Vida VL, Torregrossa G, De Franceschi M, Padalino MA, Belli E, Berggren $\mathrm{H}$, et al. Pediatric coronary artery revascularization: a European multicenter study. Ann Thorac Surg. 2013;96(3):898903. doi:10.1016/j.athoracsur.2013.05.006. [PubMed:23891408]

19. Kitamura S, Seki T, Kawachi K, Morita R, Kawata T, Mizuguchi K, et al. Excellent patency and growth potential of internal mammary artery grafts in pediatric coronary artery bypass surgery. New evidence for a "live" conduit. Circulation. 1988;78(3 Pt 2):I129-39. [PubMed:3261649]

20. Kameda Y, Kitamura S, Taniguchi S, Kawata T, Mizuguchi K, Nishioka $\mathrm{H}$, et al. Differences in adaptation to growth of children between internal thoracic artery and saphenous vein coronary bypass grafts. J Cardiovasc Surg (Torino). 2001;42(1):9-16. [PubMed: 11292899]

21. El-Khouri HM, Danilowicz DA, Slovis AJ, Colvin SB, Artman M. Saphenous vein graft growth 13 years after coronary bypass in a child with Kawasaki disease. Ann Thorac Surg. 1998;65(4):1127-30. [PubMed: 9564940]

22. Wakisaka Y, Tsuda E, Yamada O, Yagihara T, Kitamura S. Long-term results of saphenous vein graft for coronary stenosis caused by Kawasaki disease. Circ J. 2009;73(1):73-7. [PubMed: 19047778]

23. Tsuda E, Fujita H, Yagihara T, Yamada O, Echigo S, Kitamura S Competition between native flow and graft flow after coronary artery bypass grafting. Impact on indications for coronary artery bypass grafting for localized stenosis with giant aneurysms due to Kawasaki disease. Pediatr Cardiol. 2008;29(2):266-70. doi: 10.1007/s00246-007-9114-y. [PubMed:17917764]

24. Kitamura S, Tsuda E, Kobayashi J, Nakajima H, Yoshikawa Y, Yagihara T, et al. Twenty-five-year outcome of pediatric coronary artery bypass surgery for Kawasaki disease. Circulation. 2009;120(1):60-8. doi: 10.1161/CIRCULATIONAHA.108.840603. [PubMed:19546384]

25. Inoue T, Otaki M, Oku H, Fukuda T, Shinohara T. Follow-up study of coronary artery bypass grafting in patients with Kawasaki disease. Am Heart J. 2001;142(4):740-4. doi: 10.1067/mhj.2001.117316. [PubMed:11579368]

26. Kitamura S. Physiological and metabolic effects of grafts in coronary artery bypass surgery. Circ J. 2011;75(4):766-72. [PubMed: 21415547]

27. Ogawa S, Ohkubo T, Fukazawa R, Kamisago M, Kuramochi Y, Uchikoba Y, et al. Estimation of myocardial hemodynamics before and after intervention in children with Kawasaki disease. $J$ Am Coll Cardiol. 2004;43(4):653-61. doi:10.1016/j.jacc.2003.10.032. [PubMed:14975478]

28. Botman CJ, Schonberger J, Koolen S, Penn O, Botman H, Dib N, et al. Does stenosis severity of native vessels influence bypass graft patency? A prospective fractional flow reserve-guided study. Ann Thorac Surg. 2007;83(6):2093-7. doi: 10.1016/j.athoracsur.2007.01.027. [PubMed:17532405]

29. Ferguson TB, Chen C, Babb JD, Efird JT, Daggubati R, Cahill JM. Fractional flow reserve-guided coronary artery bypass grafting: can intraoperative physiologic imaging guide decision making? J Thorac Cardiovasc Surg. 2013;146(4):824-835 e1. doi:10.1016/j. jtcvs.2013.06.026. [PubMed: 23915918]

30. Kitamura S. The role of coronary bypass operation on chil- 
dren with Kawasaki disease. Coron Artery Dis. 2002;13(8):437-47. [PubMed:12544719]

31. Kitamura S. Advances in Kawasaki disease bypass surgery for coronary artery obstructions. Prog Pediatr Cardiol. 2004;19(2):167-77. doi:10.1016/j.ppedcard.2004.08.011.

32. Tsuda E, Kitamura S, Kimura K, Kobayashi J, Miyazaki S, Echigo $S$, et al. Long-term patency of internal thoracic artery grafts for coronary artery stenosis due to Kawasaki disease: comparison of early with recent results in small children. Am Heart J 2007;153(6):995-1000. doi: 10.1016/j.ahj.2007.03.034. [PubMed: 17540201]

33. Domoto S, Nakano K, Kodera K, Asano R, Fujibayashi M, Takeuchi Y. Histopathology of the longest-lived saphenous vein graft in a patient with Kawasaki disease. Ann Thorac Surg. 2012;93(6):2065 7. doi:10.1016/j.athoracsur.2011.10.068. [PubMed: 22632509]

34. Kawachi K, Kitamura S, Seki T, Morita R, Kawata T, Hasegawa J, et al. Hemodynamics and coronary blood flow during exercise after coronary artery bypass grafting with internal mammary arteries in children with Kawasaki disease. Circulation. 1991;84(2):618-24. [PubMed: 1860205]

35. Tsuda E, Hirata T, Matsuo O, Abe T, Sugiyama H, Yamada O. The 30-year outcome for patients after myocardial infarction due to coronary artery lesions caused by Kawasaki disease. Pediatr Cardiol. 2011;32(2):176-82. doi: 10.1007/s00246-010-9838-y. [PubMed: 21120463]

36. Tsuda E, Hamaoka K, Suzuki H, Sakazaki H, Murakami Y, Nakagawa $\mathrm{M}$, et al. A survey of the 3-decade outcome for patients with giant aneurysms caused by Kawasaki disease. Am HeartJ.2014;167(2):24958. doi:10.1016/j.ahj.2013.10.025. [PubMed: 24439987]

37. Matsuura K, Kobayashi J, Bando K, Niwaya K, Tagusari O, Nakajima $\mathrm{H}$, et al. Redo off-pump coronary bypass grafting with arterial grafts for Kawasaki disease. Heart Vessels. 2006;21(6):361-4. doi:10.1007/s00380-006-0912-6. [PubMed: 17143711]

38. Codispoti C, Boyd S, Sees D, Conner W. Symptomatic coronary obstruction due to Kawasaki disease in an adult. Ann Thorac Surg. 2008;85(3):1081-3. doi: 10.1016/j.athoracsur.2007.08.032. [PubMed:18291205]

39. McCrindle BW. Kawasaki disease: a childhood disease with important consequences into adulthood. Circulation. 2009;120(1):68. doi:10.1161/CIRCULATIONAHA.109.874800. [PubMed:19546382]

40. Gersony WM. The adult after kawasaki disease the risks for late coronary events. J Am Coll Cardiol. 2009;54(21):1921-3. doi 10.1016/j.jacc.2009.06.057. [PubMed:19909871]

41. Shimizu T, Hirayama T, Koizumi N, Ishimaru S, Nakai H, Tsuchida H. Surgical management of arteriosclerotic coronary artery aneurysm. J Cardiovasc Surg (Torino). 1999;40(4):535-8. [PubMed: 10532212]

42. Ramankutty R, Albacker TB, Reyes KG, Navia JL. Successful management of a posterior saccular coronary artery aneurysm at the left main coronary artery bifurcation. J Card Surg. 2011;26(1):37-9. doi:10.1111/j.1540-8191.2010.01030.x. [PubMed: 20459453]

43. Okumori M, Tokuno S, Nogami Y, Kann I, Tanaka Y. Treatment of a giant coronary artery aneurysm in an adult with a history of Kawasaki disease by resection and bypass grafting: report of a case. Surg Today. 1995;25(4):373-7. [PubMed: 7633132]

44. Abe M, Suzuki N, Katsube Y, Fukazawa R, Kamisago M, Ohkubo T, et al., editors. Evaluation of down-sizing operation for coronary giant aneurysm after Kawasaki disease.; Program and Abstracts of the Ninth International Kawasaki Disease Symposium, Taipei, Taiwan.; 2008.

45. Waki K, Baba K. Transcatheter polytetrafluoroethylene-covered stent implantation in a giant coronary artery aneurysm of a child with Kawasaki disease--a potential novel treatment. Catheter Cardiovasc Interv. 2006;68(1):74-7. doi: 10.1002/ccd.20808. [PubMed: 16763997]

46. Ishii M, Ueno T, Ikeda H, Iemura M, Sugimura T, Furui J, et al. Sequential follow-up results of catheter intervention for coronary artery lesions after Kawasaki disease: quantitative coronary artery angiography and intravascular ultrasound imaging study. Circulation. 2002;105(25):3004-10. [PubMed: 12081995]

47. Muta H, Ishii M. Percutaneous coronary intervention versus coronary artery bypass grafting for stenotic lesions afte Kawasaki disease. J Pediatr. 2010;157(1):120-6. doi: 10.1016/j. jpeds.2010.01.032. [PubMed: 20304414]

48. Medical Tribune National Survey Group of Kawasaki Disease: Report of the 22nd National Survey of Kawasaki disease. 2013.

49. Holman RC, Curns AT, Belay ED, Steiner CA, Schonberger LB. Kawasaki syndrome hospitalizations in the United States, 1997 and 2000. Pediatrics. 2003;112(3 Pt1):495-501. [PubMed: 12949272 ]

50. Newburger JW, Fulton DR. Coronary revascularization in patients with Kawasaki disease. J Pediatr. 2010;157(1):8-10. doi 10.1016/j.jpeds.2010.04.008. [PubMed:20472246]

51. Mavroudis C, Backer CL, Muster AJ, Pahl E, Sanders JH, Zales VR, et al. Expanding indications for pediatric coronary artery by pass. J Thorac Cardiovasc Surg. 1996;111(1):181-9. doi: 10.1016/S00225223(96)70415-4. [PubMed: 8551764]

52. Kwak JH, Song J, Kang IS, Huh J, Lee HJ. Changes in coronary perfusion after occlusion of coronary arteries in Kawasaki disease. Yonsei Med J. 2014;55(2):353-9. doi: 10.3349/ymj.2014.55.2.353. [PubMed: 24532503]

53. Kitamura S, Kawachi K, Nishii T, Taniguchi S, Inoue K, Mizuguchi $\mathrm{K}$, et al. Internal thoracic artery grafting for congenital coronary malformations. Ann Thorac Surg. 1992;53(3):513-6. [PubMed 1540074]

54. Mavroudis C, Backer CL, Duffy CE, Pahl E, Wax DF. Pediatric coronary artery bypass for Kawasaki congenital, post arterial switch, and iatrogenic lesions. Ann Thorac Surg. 1999;68(2):506-12. [PubMed: 10475420]

55. Viola N, Alghamdi AA, Al-Radi OO, Coles JG, Van Arsdell GS, Caldarone CA. Midterm outcomes of myocardial revascularization in children. J Thorac Cardiovasc Surg. 2010;139(2):333-8. doi:10.1016/j. jtcvs.2009.09.005. [PubMed: 20005530]

56. Legendre A, Chantepie A, Belli E, Vouhe PR, Neville P, Dulac Y, et al. Outcome of coronary artery bypass grafting performed in young children. J Thorac Cardiovasc Surg. 2010;139(2):349-53. doi 10.1016/j.jtcvs.2009.07.061. [PubMed:19775706]

57. Daniels LB, Tjajadi MS, Walford HH, Jimenez-Fernandez S, Trofimenko V, Fick DB, et al. Prevalence of Kawasaki disease in young adults with suspected myocardial ischemia. Circulation. 2012;125(20):2447-53. doi: 10.1161/CIRCULATIONAHA.111.082107. [PubMed: 22595319]

58. Kalfa D, Belli E. Coronary artery bypass grafting Coronary artery bypass grafting in children younger than 15 years old. In: Franco KL, Thourani VH, editors. Cardiothoracic Surgery Review. Philadelphia: Lippincott Williams \& Wilkins; 2012. pp. 1647-51.

59. Cooley DA, McNamara DG, Duncan JM, Ott DA. Internal mammary-anomalous left anterior descending coronary artery graft in 16-month-old infant with tetralogy of Fallot: 30-month followup. Ann Thorac Surg. 1980;30(6):588-91. [PubMed: 7469579]

60. Yacoub M. Kawasaki disease--from a mystery to a paradigm Coron Artery Dis. 2002;13(8):421-2. [PubMed:12544716] 